Volumen 19 n$^{\circ} 22016$

\title{
Editorial
}

\section{El gasto sanitario en las diferentes comunidades autónomas de España}

El Consejo Económico y Social español (en el que están organizaciones empresariales sindicales y otras representativas de los intereses de la ciudadanía), alto órgano consultivo del Gobierno, ha publicado recientemente el gasto sanitario por habitante en 2015 de las 17 Comunidades Autónomas (CCAA), cuyos sistemas sanitarios conforman el Sistema Nacional de Salud español ${ }^{1}$.

En su Memoria Socioeconómica y Laboral señala que el pasado año el gasto medio sanitario por habitante aumentó un $1,82 \%$ de media en España, hasta los 1.232 euros, con una previsión de incremento de 3,8\% para 2016. Como puede apreciarse, se vuelve a incrementar el gasto en sanidad en nuestro país, lo cual es una buena noticia, pero los datos ponen de manifiesto la fuerte dispersión que existe en los presupuestos sanitarios regionales².

Cuando se analiza este gasto en cada CCAA, observamos que se está produciendo una diferencia cada vez mayor, entre las distintas CCAA en cuanto a la inversión en sanidad por ciudadano y año. En efecto, a la cabeza del gasto sanitario en 2015, estuvo el País Vasco que fue la comunidad que más presupuesto destinó a este capítulo, mientras que Andalucía, fue la que menos, según los datos del Consejo Económico y Social.

Galicia tiene previsto incrementar su presupuesto sanitario para este año en un 18,7\% y Aragón, un $12,6 \%$ y son las que más los suben, frente a los crecimientos del $0,8 \%$ del País Vasco 0 del $1 \%$ de Castilla y León o la estabilidad de las cuentas en Castilla-La Mancha, Cataluña y Extremadura.

El País Vasco, Navarra y Asturias fueron las comunidades con presupuestos más generosos en 2015, en tanto que Andalucía, la Comunidad Valenciana y La Rioja presupuestaron cantidades inferiores a la media nacional.

En 2015, Galicia bajó sus cuentas en sanidad respecto al año anterior en un 10,37\% y también Aragón, aunque en una menor proporción, un 0,30\%, mientras que Baleares los incrementó en un $10,30 \%$.

En cuanto al gasto por habitante, frente a los 1.584 euros que destinó el País Vasco el pasado año, Andalucía dedicó 1.007 euros, un 36\% menos. Por encima de los 1.232 euros de media se colocaron Asturias (1.423,53€), Cantabria (1.348 €), Canarias (1.253,81 €), Castilla y León (1.325,10 $€)$, Extremadura (1.284,98 €), País Vasco y Navarra $(1.457,41 €)$. Por debajo se situaron Andalucía, Aragón (1.214,43 €), Baleares (1.193,40 €), Castilla-La Mancha $(1.176,77 €)$, Cataluña $(1.127,71 €)$, la Comunidad Valenciana (1.102,86 €), Galicia $(1.083,27 €)$, Madrid $(1.132,90 €)$, Murcia $(1.123,45 €)$ y La Rioja $(1.114,74 €)$. 
EI CES precisa que no existe una relación directa entre el gasto per cápita y la calidad del servicio prestado, pues factores como la media de edad de la población o la dispersión de los habitantes, con una menor densidad de población, aumentan el presupuesto medio por persona.

No obstante, es importante conocer la realidad de la inversión en sanidad desde los datos oficiales y no desde un punto de vista ideológico, pues en este país me temo que todo lo analizamos desde el lado emocional y no desde la objetividad de los hechos.

Estas diferencias en cuanto a inversión en sanidad, por parte de las CCAA, están totalmente en contra de la letra y filosofía de la Ley 16/2003 de cohesión y calidad del Sistema Nacional de Sa$\operatorname{lud}^{3}, \mathrm{y}$ antes o después, tendrán su repercusión en la calidad de la atención sanitaria que reciben los ciudadanos, independientemente de la eficacia de cada sistema.

Pero además, estas diferencias comienzan a ser palpables en cuanto a la contratación de personal sanitario por parte de las distintas CCAA. De hecho, el mayor ajuste económico por la crisis lo han sufrido los profesionales sanitarios; y dentro de este ajuste el personal sanitario que más expuesto ha estado y está a esta situación, es el de las CCAA que menos invierten en sanidad por habitante y año.

Rodolfo Crespo Montero

Director Enfermería Nefrológica

\section{Referencias}

${ }^{1}$ http://www.ces.es/

2 http://www.ces.es/documents/10180/3933980/Memoria-CES- 2015_capitulo3.pdf.

${ }^{3}$ Ley 16/2003, de 28 de mayo, de cohesión y calidad del Sistema Nacional de Salud. 